\title{
The Application Model of Internet Platform in Supply Chain Finance
}

\author{
Xiaoli Duan ${ }^{1, a^{*}}$ and Chi Zhang ${ }^{2, b}$ \\ ${ }^{1}$ Institute of Economics and Management, Zhengzhou Normal University, Zhengzhou, Henan Province , \\ China \\ ${ }^{2}$ International Business Administration School, Shanghai University of Finance and Economics, \\ Shanghai, China \\ a2572458883@qq.com, bDxly205@126.com
}

\section{Keywords: Supply Chain Finance; E-Commerce; Visualization Operation Mode1 INTRODUCTION}

\begin{abstract}
By integrating logistics with capital flow and information flow effectively, supply chain finance revitalize the funds of the whole supply chain, foster innovation in financial products and services. From the perspective of e-commerce, based the analysis of supply chain finance model, function and market risk, the paper explored commercial banks to carry out internet platform and improve the financial efficiency of supply chain through mainstream business ,model innovation and risk control.
\end{abstract}

\section{Introduction}

Financing has been a major bottleneck restricting the survival and development of small and medium-sized enterprises. In recent years, as an innovative means of financing, supply chain finance has gradually become effective way for SMEs (small and medium-sized enterprises)to obtain working assets.

The supply chain is system chain which taking the original supplier as the logical starting point and end consumers as the logical end point, include procurement, processing, assembly, packaging, transportation, distribution and other activities during the whole business. In a word, it relates to four basic disposal operation module including the production planning, resource procurement, assembly production, distribution and marketing. Supply chain finance make an effectively integration of the logistics, capital flow, information flow, and revitalize the funds of the whole supply chain.

Hofmann (2005) believes that the supply chain finance (SCF) is an interdisciplinary cooperation involving logistics, supply chain management,and finance. Through cross organizational planning of financial resources, operation and control, the inside and outside supply chain participants together create value[1]. In general, supply chain finance is the integrated management system of capital flow of supply chain, and enhance the efficiency of funds flow of the whole supply chain. In a narrow sense, the supply chain finance is the financing plan according to the transaction object, including accounts receivable pledge, factoring financing, credit / inventory pledge financing and warehouse financing etc. Supply Chain Finance (SCF) can be understood as a combination of supply chain and finance. All of the financial supply chain as a carrier in the part of each stage combine together, to solve the problem of funds for each customer, to carry out comprehensive financial services.

Supply Chain Finance serves the core enterprises, nearby enterprises, the end user and so on. it provide a wide variety of services, including consulting services, financial services and other services. The financial supply chain effectively integrated "production, supply, sales of each node" in the entire supply chain[2], with good credit as a guarantee of the core enterprise, innovative financial products and services, not only it solves financing difficult problem of the small and medium-sized enterprise for a long time, but also it conducive to promoting the upgrading and development of related industries, and the introduction of third party logistics, reduce the credit risk from bank, expand basic business scope, promoting inter-bank development and competition. In short, the supply chain Finance can achieve a win-win situation for both financial system and enterprises in china. 
Table 1 Comparison of traditional financing model and SCF

\begin{tabular}{|c|c|c|}
\hline Terms & Conventional financial & SCFs \\
\hline Credit subject & single enterprise & Business Groups \\
\hline pawn & $\begin{array}{l}\text { There are core assets and third } \\
\text { party guarantors }\end{array}$ & Movable goods \\
\hline Rating methods & The main rating & The main rating and debt rating \\
\hline Rating range & enterprise & Enterprise supply chain \\
\hline banks to entry & static state & dynamic \\
\hline risk & High & low \\
\hline Service varieties & simplification & diversify \\
\hline service efficiency & low & High \\
\hline term of service & Short-term credit demand & Long-term credit demand \\
\hline roles & $\begin{array}{c}\text { Alleviate the temporary needs } \\
\text { of enterprises }\end{array}$ & $\begin{array}{c}\text { Enhancing long-term } \\
\text { competitiveness of enterprises }\end{array}$ \\
\hline
\end{tabular}

Source: http://www. epub.cnki.net (In Chinese).

With the rapid development of e-commerce, information technology has penetrated the economic, management. The combination of supply chain and e-commerce represents the general trend in the information age. The electricity supplier operating as the core line of supply chain finance plays an important role. Customers form a huge database of e-commerce transactions, the supply chain enterprises based on e-business platform credit data as a supplement to the financial credit transaction process, optimization model, and based on cloud computing, big data technology, to strengthen supply chain network and virtual supply chain network can effectively reduce the information asymmetry between the fund industry in the Internet platform and small-medium sized enterprises. As a supplement to the financial credit, the information flow, logistics and capital flow, collaborative risk carrier, reduce financial risk in supply chain. Previous studies have found that the information asymmetry is the biggest obstacle to effective financing of small and medium sized enterprises (Stiglitz and Weiss, 1981; Jiang et al., 2014) [3]。The introduction of e-commerce increases the visibility of the supply chain finance and reduces the risks caused by asymmetric information.

Based on the perspective of e-commerce, through the analysis of the significance of e-commerce and supply chain financial integration, this paper puts forward some countermeasures and suggestions for the development of Supply Chain Finance.

\section{The Application of Internet Platform in the Development of Supply Chain Finance}

The Internet financial supply chain system is suitable for the operation of enterprises, the supply chain of P2O industry, enterprise group finance companies, B2B business, purchasing platform, financial institutions, import factoring companies, large core enterprises, financial information services company.

Application of Supply Chain Technology Internet Platform. Supply chain finance emphasizes mutual benefits. Therefore, the parties should set up contract of supply chain partnership, through constructing the information technology platform, to make the supply chain visibility as possible. In the practice of SCFs, mostly related to the application of Internet platform: one is technical platform is directly provided by the financial institutions; the other is through the third party e-commerce institutions, financial institutions just launched fund-raising business. This technology has contributed to the visibility 
of transaction information among the buyer, the seller and the financial institutions, and provide real-time transaction credit records for enterprise financing[4].

The IT technology supplier is SCF promoters, they provide a connection of commodity trading and financing transactions transparent platform, the platform is able to discover the key events to trigger risk in SCF[5]. Obviously, the foreign financial institutions is to establish the key event in the supply chain on the basis of SCF, such as the purchase orders and obtain invoices. Through this platform not only financial institutions to track key events and timely respond to the financing needs of enterprises, but also the sharing of information and data, reduce the cost of financing and transaction risk. Cavenaghi(2014) held that the core of the SCFs is to accelerate the use of funds constantly updated data flow through the third party information platform, shorten the transit time between supplier and demand of funds. At the same time the banks reduced loan risk[6].

In China, along with the comprehensive reform of the Internet in financial markets, the supply chain finance online has constantly development. According to the traditional mode of financing model, it is difficult for the banks to make evaluation of low information transparency, banks need to match bills with credit. While online supply chain visibility platform, can help to solve the problem of non transparent information.At present, the SCFs is in the integration period of online supply chain financial restructuring . Based on the original model Lian Ziying scholars made a model of " $1+1+\mathrm{SCE}$ " is put forward, To construct the three party cooperation platform and provide the fund management service for the whole supply chain[7]. Shi Jinzhao(2015) reveals the supply chain finance online three paths: one is the evolution of SCF2.0, which realizes online SCF from the traditional line; the other is the electricity supplier SCFs, micro-finance business who obtained licenses can provide financing services, such as small loan; the third is SCF based on the supply of bank business platform: to provide financing services relying on the self or the third party e-commerce platform[8].

Supply Chain Visualization Platform Model. First, Visual operation model of order. The order of visual interface can provide credit to the bank, the entire supply chain cooperation process showed that the prediction, ordering, acceptance and financing, and track order status. This information can be used as reference for the assessment of bank credit.First, the confirmation stage: the downstream enterprises to fill in the purchase order, upstream suppliers according to the platform information to decide whether to accept the order. Second, the delivery stage: supplier approval in accordance with the contract order after delivery. Downstream enterprises confirm the receipt. Third, the payment stage: the upstream enterprise issued invoices, and then by the downstream enterprises receiving and payment. In the whole process, the use of bank visualization platform for real-time tracking monitoring of operation, better treatment and prevention of information imbalance problem.

The Internet supply chain finance system is a financial information service platform that connects with all stakeholders in the supply chain finance business as shown Fig. 1.

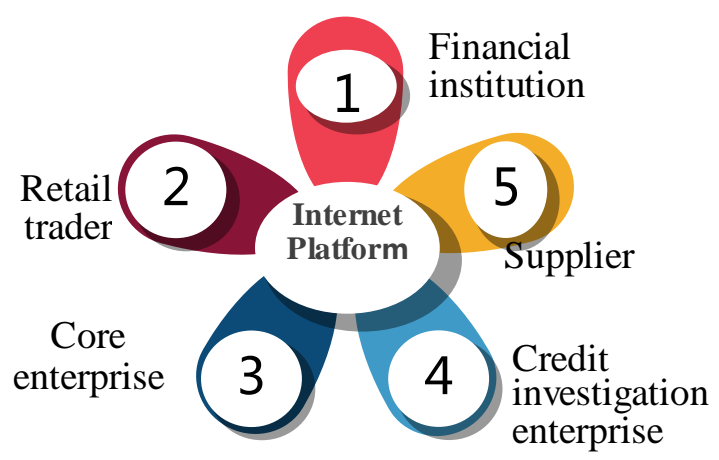

Figure 1. the main stakeholders in the supply chain finance

Secondly, the mode of operation of the logistics visualization. Logistics service mode of a real-time visualization is dependent on the Internet, it can reflect the dynamic nature of the goods circulation, and the dynamics of node enterprise asset . Banks can understand the flow of goods and purchase orders from 
the real-time information of goods, goods sales orders, in order to monitor the risk of the goods and the operation level.

The transfer of accounts receivable financing refers to the suppliers according to the settlement issued in the future by the core enterprise, with transfer the possession of settlement, at a certain price (less than a single settlement amount), acquiring the settlement amount. The method of the transfer of accounts receivable is fit for retail industry and logistics industry. After transfered, the cash will be remitted to the designated financial agency settlement account.

By using the Internet, the internet operating platform of supply chain finance is docking with ERP system of the core enterprise, based on big data and credit evaluation for reference, relying on a number of financial institutions for financing real networking. Efficient solution is provided to solve the problems of financing for core enterprise, which is the most suitable for the current SCF business model.

Last, SCF internet platform visualization operation mode. SCF internet platform can more clearly regulate all the links of the supply chain of goods storage, effective supervision and improve the bank ownership of the goods on the upstream and downstream core enterprises. Through SCF internet platform visualization platform can get all the data: raw materials, semi-finished products, finished products in processing, contacts marketing and commodity stocks. With the goods as collateral, clear information transfer through ERP of the core enterprises, contacts, accounts receivable storage of goods or raw materials can reduce the financing risk. The flow path can be conclude as Fig. 2 .

$$
\begin{gathered}
\text { Online } \\
\text { application }
\end{gathered}
$$

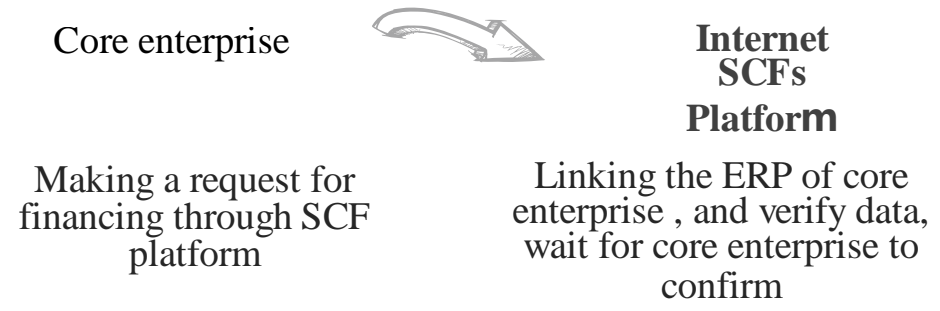

Sign a contract and offline loan

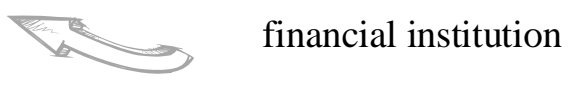

Mass processing of financial business, and selecting quality customers

Figure 2. The SCF internet platform visualization operation mode

When the core enterprise are facing fund shortage in business operations, it need make a request for financing through SCF internet platform to acquire a large amount of capital to conduct its business.

After business risk control, authenticity screening over the core enterprises who put forward to financing, according to the financing request put forward by small and medium-sized enterprise on the SCF internet platform, the internet platform will judge and select suitable financial institutions, which may be with the characteristics of lower costs and creditworthiness, for the core enterprises to loan. It will provide services such as accounts receivable turnover, inventory ownership and contact or order financing to match the need of the core enterprises. The SCF internet platform itself is only a intermediary service platform, which is normally not take participation in investment activity and involved in money.

If operating companies want to participate in capital investment in some circumstance, it can use another identity of factoring institutions settled on the SCFs internet platform.

\section{Conclusions}

Based on the platform of the Internet industry, the enterprise built the production of financial ecosystem, According to credit situation of the core enterprise determined by the relative financial institutions, the internet platform check the credit balance of enterprise, and select a short cycle, low interest rates.

Through embeding internet into industry supply chain finance, the operate system achieved good 
performance and avoided risks, therefore it enhance the competitiveness of cinventional industries. But there exists some new problems in the Internet industry platform, which is also challenges for the effective realization of supply chain financial performance. For example, contract breaking of enterprise will bring negative externalities to other enterprises in the same platform, such as collusion of suppliers taking corporate funds for other project operation between the factory, the false project manager or supplier. thus, how to control with the problems is very critical to the SCF internet platform.

In the SCF Internet platform, the government should play the role of coordinator, adpot comprehensive mechanism to build trust and reputation, By eliminating the nagative factors to keep healthy operation for the whole supply chain. keeping the formation symmetric and visualization through ERP system sharing among stakeholds and development of strategic relations. Realizing the internalization of externalities in reducing transaction costs, thereby can effectively reduce the negative spillover effects.

\section{References}

[1] Chen Xiangfeng. The supply chain financial service innovation theory [M]. Shanghai: Fudan University press,2009.pp.23-25

[2] Fang yaner. business innovation, of banking SCF in the Internet era , [N]. Shanghai Securities Journal, January 25, 2016

[3] Schmitz.H.and K. Nadvi. Clustering and Industrialization: Introduction[J]. World Development, 1999, 27 (9) pp.1503-1514.

[4] SONG Hua;LU Qiang.The Innovation of Supply Chain Finance Pattern Based on Virtual Clusters,A Case Study of SJET,China Industrial Economy2017 (5) :172-193.

[5] Michael L. A Supply Chain Finance Prime[J]. Sup-ply Chain Finance, 2007 (4): pp.34-48.

[6] Cavenaghi E. Supply-chain finance: The new frontier in the world of payments[J]. Journal of Payments Strategy \& Systems, 2014, 7(4): 290-293.

[7] Lian Ziying. "1MN" of the new financing model of supply chain finance [J]. trade era.2012(26).

[8] Shi Jinzhao, Guo Jue. The development and domestic practice of supply chain finance from the perspective of Internet[J]. Journal of Xi'an Jiao Tong University: Social Sciences printing plate, 2015,35(4):10-16.

[9] Song Hua, Chen Sijie. Evolution of supply chain finance and Internet supply chain finance: a theoretical framework [J]. Journal of Renmin University of China,2016,(5):pp.95-104.

[10] Song Hua. Supply chain finance [M]. Beijing: Renmin University of China press,2015. 